\title{
DEVELOPMENT AND TEST OF BLIMP-BASED COMPACT LIDAR POWEWR-LINE INSPECTION SYSTEM
}

\author{
W.W. Pan ${ }^{\text {a,* }}$, Y.J. Dou ${ }^{\text {a }}$ G.L. Wang ${ }^{\text {a }}$ M.X. Wu ${ }^{\text {b }}$, R.G. Ren ${ }^{\text {b }}$, X. Xu ${ }^{\text {b }}$ \\ a China Academy of Engineering Physics - 25273221@qq.com \\ ${ }^{\mathrm{b}}$ Mianyang Skyeye Laser Technology Co. Ltd. - 303781616@qq.com
}

Commission WG I/2 III/4

KEY WORDS: Compact LIDAR, Unmanned blimps, Transmission line inspection, Flight along power-line, Safety hazards analysis

\begin{abstract}
:
This paper introduces a compact LIDAR system designed to inspect overhead transmission line for maintenance purposes. This LIDAR system is carried by a small unmanned helium airship, which is guided by GPS and laser ranging to fly automatically along the power-line over a limited distance. The 3D coordinates of the power line, power tower and power line channel features are gathered by LIDAR. Test have been accomplished using this blimp-based compact LIDAR power-line inspection system. Its inspections of a $500 \mathrm{kV}$ power lines also shows the high efficient inspection, less risk to personnel and more inspections per day compared with manual inspection.
\end{abstract}

\section{INTRODUCTION}

The maximum paper length is restricted to 8 pages. Invited papers can be increased to 12 pages. The paper should have the following structure:

It is necessary to regularly inspect over-head power line for its security risk in advance in order to ensure that the power line transmission system works well and reliably. Traditionally, power-lines have been inspected for damage to structure and deterioration of insulators by employees traversing the lines on ground transportation or on foot. This cannot fully meet the needs of modern power grid construction and development. EHV and UHV power grid in future call for advanced and efficient power-line inspection technology.

Power line maintenance inspection with airborne LIDAR can improve efficiency, reduce the costs and does not hazard crews. This efficient, economical and safe method of transmission line inspection has started to become a hot research. Currently power line inspection with airborne LIDAR mainly use heavy LIDAR which costs about 10 million in RMB and has less advantage in cost than manual inspection, especially in southwest region of China. Therefore, research has been carried out using UAV-based LIDAR for the inspection of power lines in USA and China.

In USA, the Electric Power Research Institute reported that a smaller and simpler LIDAR system with reduced range could be designed if there were a market need and that present there does not appear to be a market that would justify development over the next 20 years in "Future Inspection of Overhead Transmission Lines" in 2008. But in the its 2013 annual report that UAVs carry an LiDAR to performing a variety of power line inspections

In China, China Academy of Engineering Physics and State Grid Corporation of China had performed the unmanned aerial vehicle carried compact lidar power-line inspection technology research.

In this paper, a compact LIDAR integrated with an unmanned helium blimp is proposed and tested for power-line inspection. An unmanned blimp can be guided along the power-line with the autonomous flight control algorithm coupled with the laser ranging data. This method has an easier access and less risk to personnel and improve the efficiency of power-line inspection, and it cost less.

\section{SYSTEM ARCHITECTURE}

The following items are the major components and their technical features of the power-line inspection system (Figure $1)$.

The camera uses a 22 million pixels full-frame digital camera with $24 \mathrm{~mm}$ focal length, $6.4 \mu \mathrm{m}$ pixel size and $1 / 1000$ second exposure time.

Laser scanner: the farthest detection distance is about $350 \mathrm{~m}$, ranging accuracy is $15 \mathrm{~mm}$, scanning fan angle is $\pm 40^{\circ}$, scan linear speeds is up to 65 lines/second, the maximum repetition rate is $30 \mathrm{kHz}$, rotating prism angular resolution is $0.01^{\circ}$.

Position and Orientation System (POS): with $1 \mathrm{~Hz}$ GPS satellite signal data acquisition, $100 \mathrm{~Hz}$ attitude angle data processing and analysis capabilities; positioning accuracy is about $0.05 \mathrm{~m}$, $0.05 \mathrm{~m}, 0.1 \mathrm{~m}(\mathrm{RMS})$; attitude accuracy is about $0.02^{\circ}, 0.02^{\circ}$, $0.05^{\circ}(\mathrm{RMS})$.

Airborne computer has a "one-click" setting function including various parameters for this compact LIDAR. It real-time records data of position, attitude, laser scanner's ranging and rotating prism angle, as well as digital camera's shutter time signal, Figure 1(a). Meanwhile, onboard computer also in real time identifies and extracts laser point cloud data of the power lines, then the distance between the blimp and power lines is

\footnotetext{
* PAN Wenwu, main interests are LIDAR and its applications research, email:25273221@qq.com.
} 
calculated and sent to the blimp's flight control system to guide the blimp flying along the power-line over a fixed height.

By optimized LIDAR layout design and electromagnetic compatibility consideration, the compact LIDAR for power-line inspection weighs only $22.5 \mathrm{~kg}$ (including battery) and has dimensions of $500 \mathrm{~mm} \times 360 \mathrm{~mm} \times 180 \mathrm{~mm}$. A formula for calculating LIDAR positioning accuracy shows that using this compact inspection system can obtain $0.285 \mathrm{~m}$ horizontal accuracy and $0.209 \mathrm{~m}$ elevation accuracy at $125 \mathrm{~m}$ relative flight altitude when prism reflect plane angle is $40^{\circ}$.

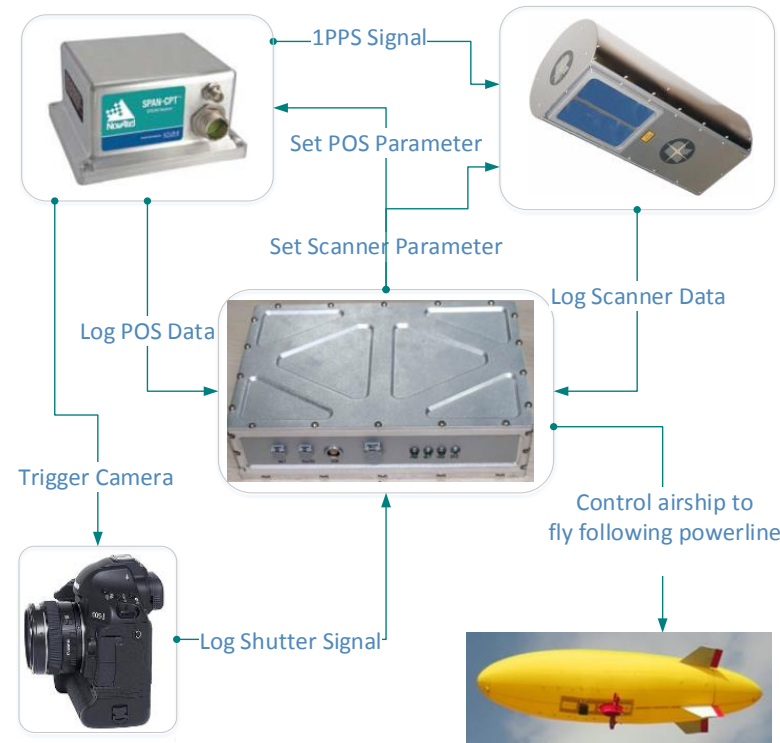

a) Power-line inspecting system architecture

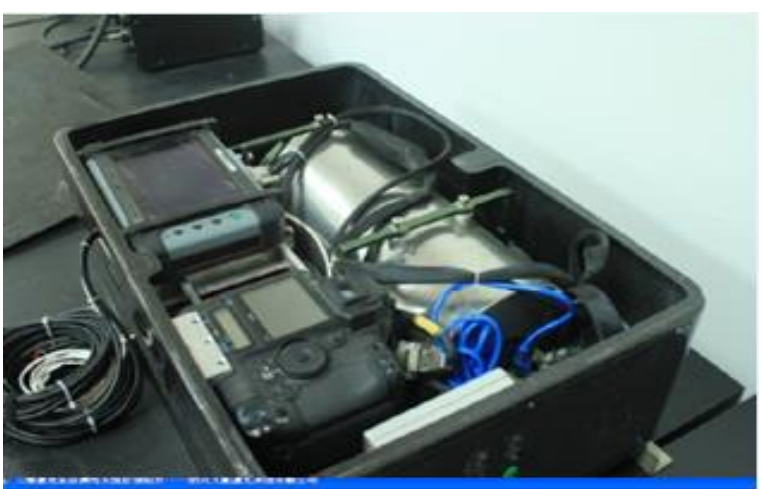

พw*nkm

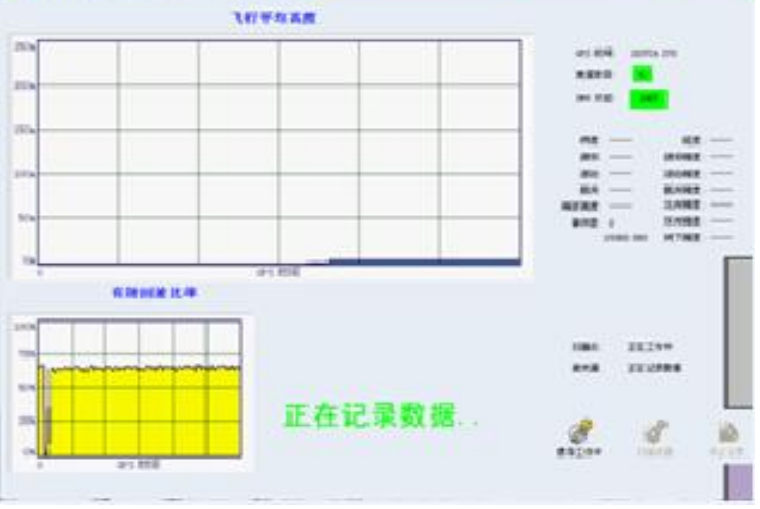

b) Devices and control software photo

Figure 1. Architecture and photo of this compact LIDAR

As other LIDAR, time accurate synchronization is realized by 1PPS signal sent by the GPS receiver between GPS and scanner. And the digital camera shutter time is captured and then sent to the GPS receiver, so the accurate digital image capture time is recorded.

\section{DIGITAL CAMERA CALIBRATION}

In this paper, only introduce the matching error calibration of laser point cloud and digital images. As described in the software manual of Terra Photo (trial version): planning a grid flight route (Figure 2), a helium-inflated blimp equipped with LiDAR flying along the flight route, and then obtaining the distribution of flight region's track and control points by data processing (Figure 3 ). The two wider lines are about $180 \mathrm{~m}$ high relative to the ground routes and four narrower lines are $100 \mathrm{~m}$ high routes. For calibrating digital camera parameters, 25 ground control points (GCP) is placed on the ground in an array of $5 \times 5$, each made up of $50 \mathrm{~cm} \times 50 \mathrm{~cm}$ blue tarpaulin, distributed in uniform spacing of $20 \mathrm{~m}$. With one control point in the distance of $2 \mathrm{~km}$ as the master GPS receiver, then the coordinates of each control point in the calibration field can be easily obtained.

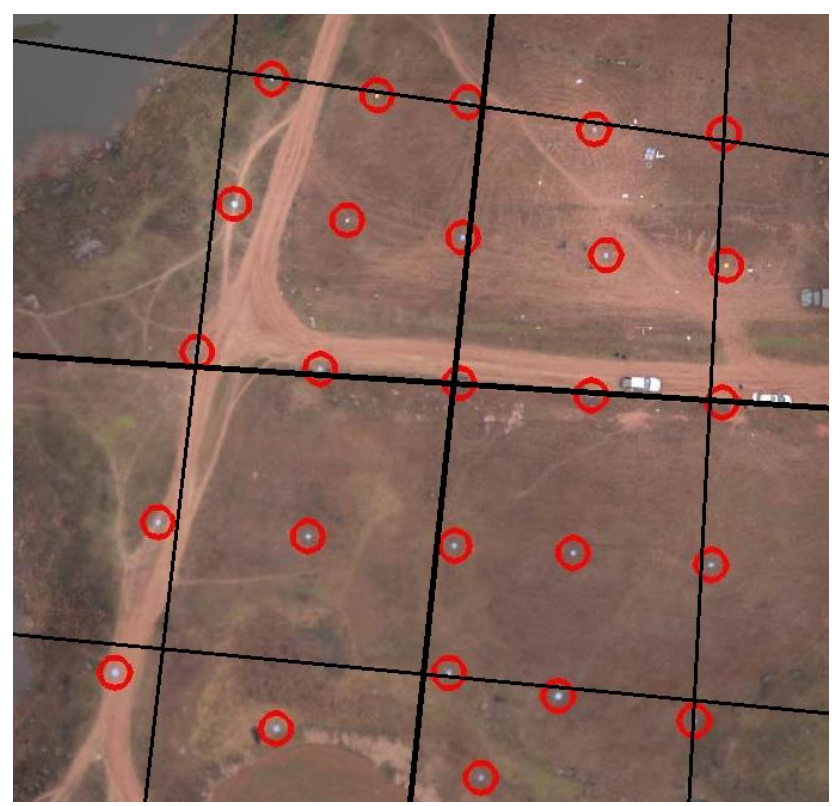

Figure 2. Control points and flight route for camera calibration

The coordinates of these control points are loaded into Terra Photo software (trial version). The software uses the known GCP coordinates for determining whether there is a systematic shift between the images and the GCPs. There are 13.03 known points and 9.03 ground points in each image. After calculation, the standard deviation reduces to $7.8525 \mathrm{~cm}$ from the initial average of $59.3469 \mathrm{~cm}$, the digital images match well with laser point clouds (Figure 3).

In Figure 3(a), the red line is the boundary of a reservoir identified by DOM (Digital Orthophoto Map), and the yellow line is the same boundary of this reservoir identified by laser point cloud. Obviously, the DOM do not matches the laser point cloud. After applied the calibrated main point and lens distortion parameters of camera, the DOM do match the laser point cloud well, shown as Figure 3(b). 


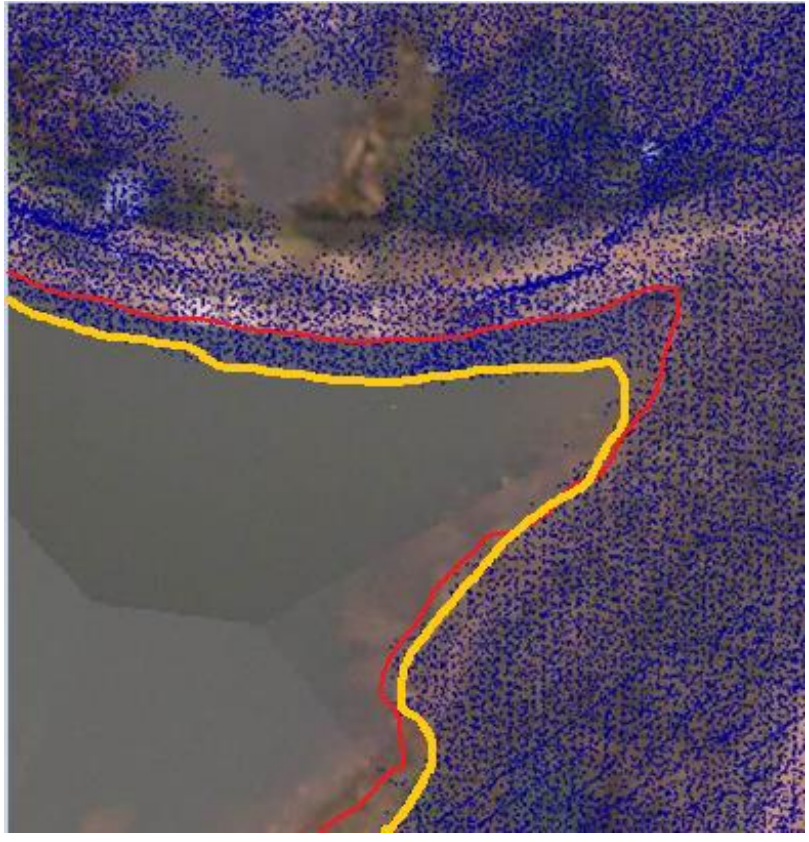

a) Digital orthophoto map superposition of point cloud before digital camera calibrated

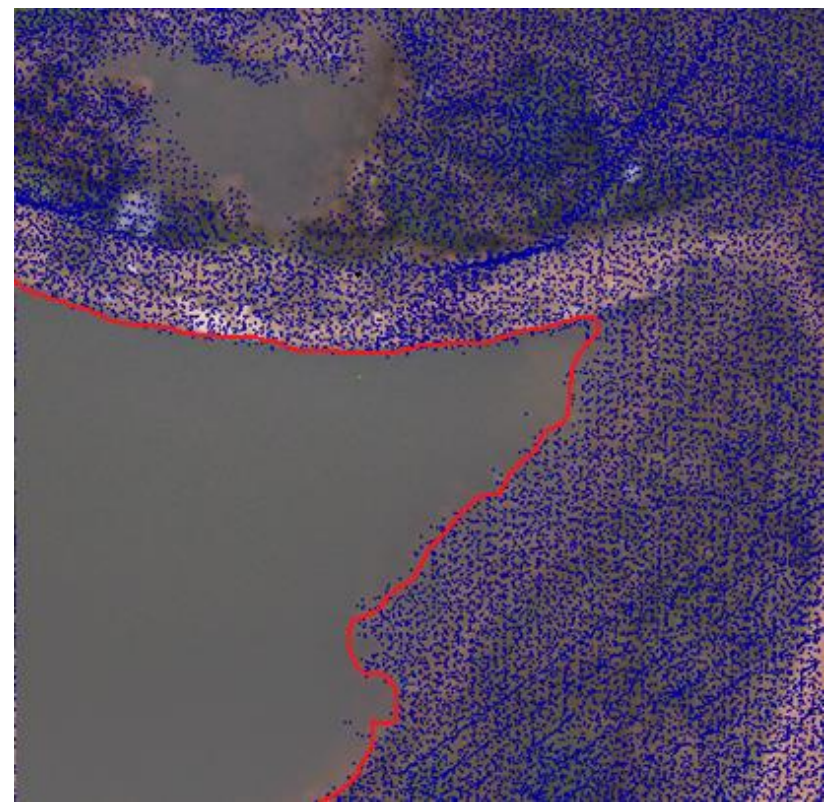

b) Digital orthophoto map superposition of point cloud after digital camera calibrated

Figure 3. Comparison of match calibration of laser point clouds and digital images

The calibrated main point and lens distortion parameters of camera are shown in Table 1, while the camera installation error is also exactly solved: heading is $0.0954^{\circ}$, roll is $-0.7181^{\circ}$, pitch is $-0.7435^{\circ}$.

\begin{tabular}{|l|l|l|}
\hline $\begin{array}{l}\text { No } \\
\cdot\end{array}$ & Calibration item & Calibration value \\
\hline 1 & Main points X0 & 18.6 pixels \\
\hline 2 & Main points Y0 & -16.3 pixels \\
\hline 3 & Focus f & 3828.38586289 pixels \\
\hline 4 & Radial distortion & -0.000000003748275 \\
\hline
\end{tabular}

\begin{tabular}{|l|l|l|}
\hline & coefficients A3 & \\
\hline 5 & $\begin{array}{l}\text { Radial distortion } \\
\text { coefficients A5 }\end{array}$ & $\begin{array}{l}0.00000000000000028 \\
17632\end{array}$ \\
\hline 6 & $\begin{array}{l}\text { Tangential } \\
\text { distortion } \\
\text { coefficients P1 }\end{array}$ & -0.000001566673 \\
\hline 7 & $\begin{array}{l}\text { Tangential } \\
\text { distortion } \\
\text { coefficients P2 }\end{array}$ & -0.000001000656 \\
\hline
\end{tabular}

Table 1. Calibrated parameters of camera

\section{FLIGHT CONTROL}

In order to effectively obtain laser point cloud data by LIDAR, it is necessary for the unmanned blimp fly along the power-line within a limited height $(75 \mathrm{~m}-100 \mathrm{~m})$ close to the lines. Meanwhile it is helpful to obtain the spatial information of power lines and the 3D data of power-line track clearance. Too high flight would gain too few point cloud and too low flight would be dangerous. Automatic flight tracking technology along power lines can guarantee an unmanned blimp is always flying in the optimal height.

In fact, precise GPS coordinates of power towers can be obtained from the power line designer which position accuracy is less than $1 \mathrm{~m}$. Therefore, the unmanned blimp can be well fly along power lines according the flight route designed by these precise power tower coordinates under the control of autonomous flight module (Figure 4a), slope calculating module (Figure 4b), variable height flight module (Figure 4c) and LiDAR's laser scan ranging data of power lines.

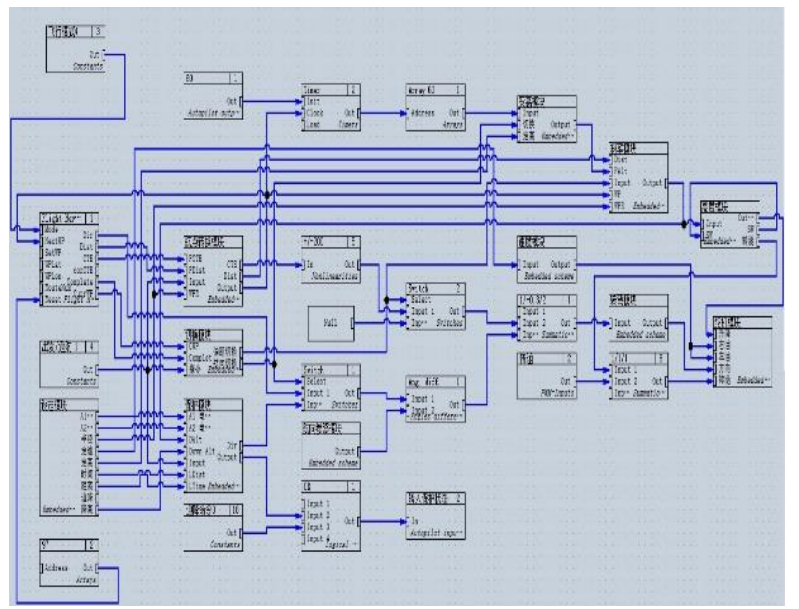

a) Control logic of constant height autonomous flight

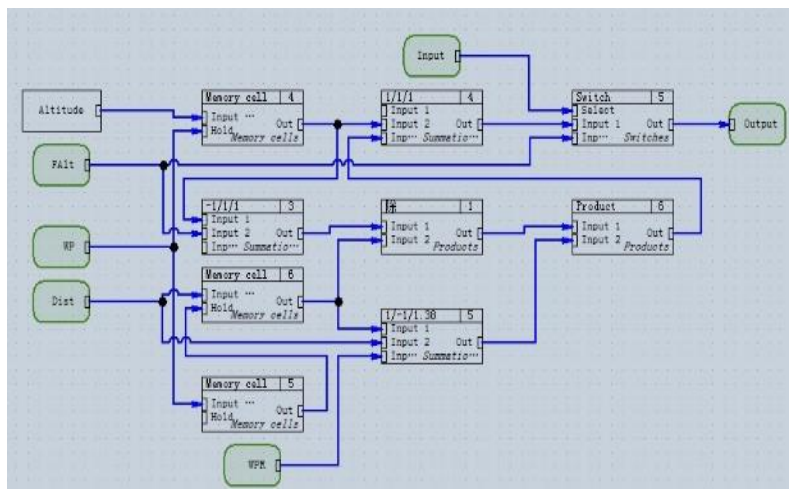

b) Slope calculating module 


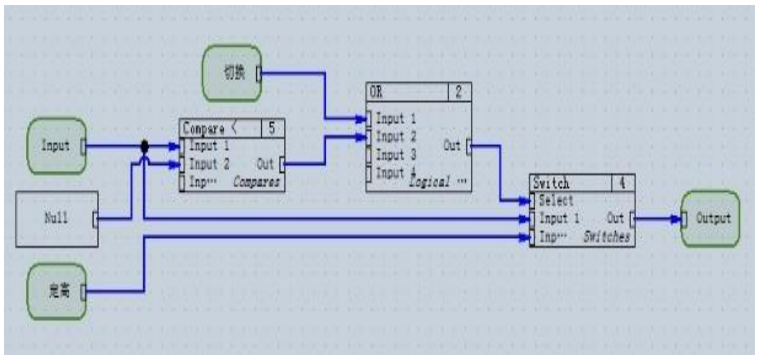

c) Variable height flight control logic

Figure 4. Control logic of autonomous variable height flight

\section{SYSTEM TEST}

To test this airborne power-line inspection system, inspection test of a $500 \mathrm{kV}$ EHV transmission line with $22 \mathrm{~km}$ length, are performed in Jiang You county (Figure 5). The Figure 6 shows blimp flight height change with the time, namely the power line, and the height variation is more than $150 \mathrm{~m}$. The point cloud of the power line, power tower and power line channel features are shown as Figure 7.

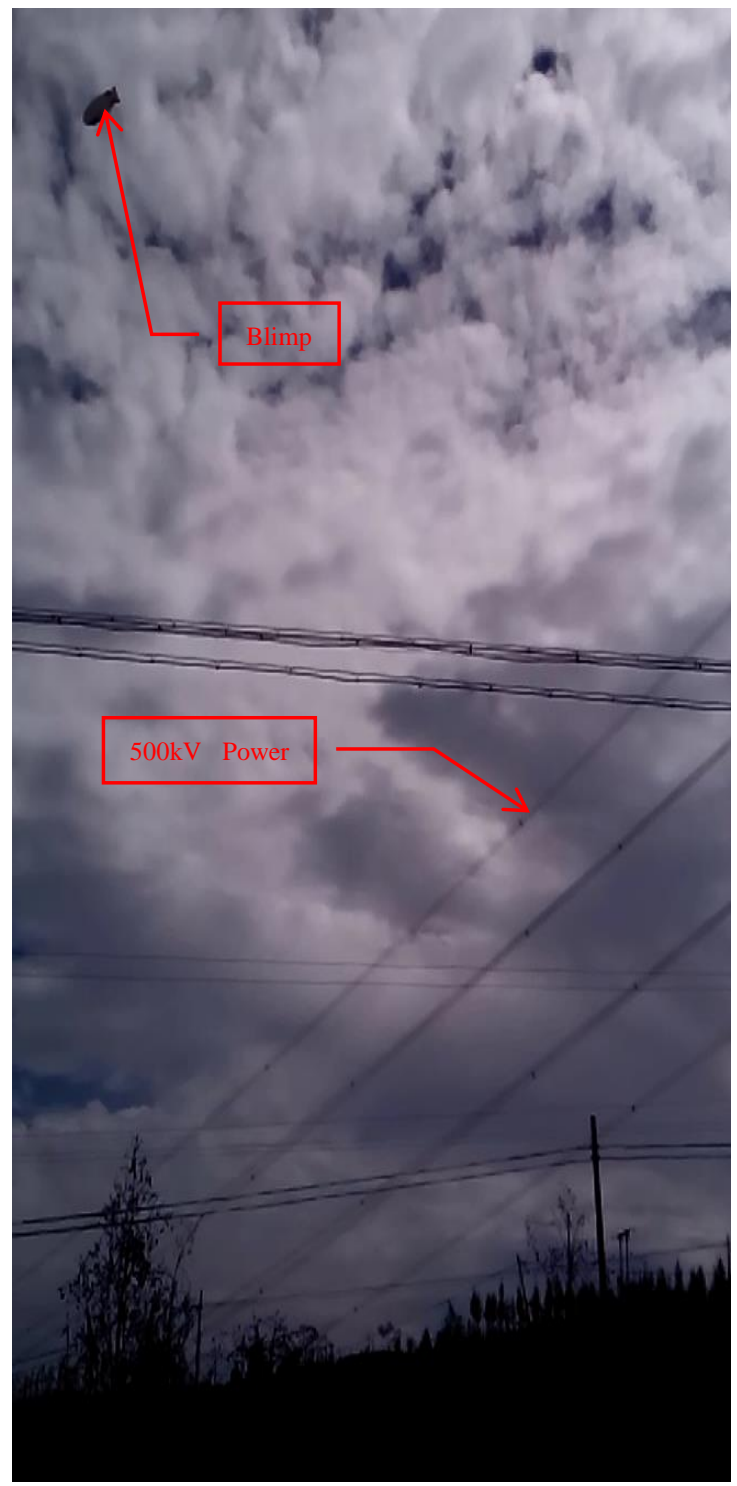

Figure 5. Power-line inspection scene

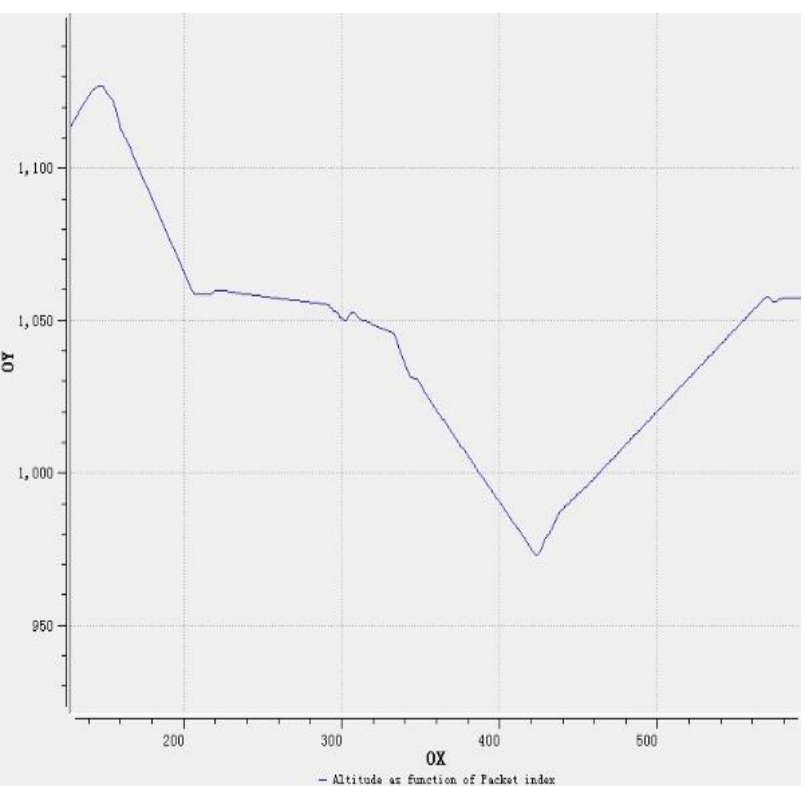

Figure 6. Track height data along power lines

A detailed description of tower coordinates extracting method is studied (Reference: Transmission wires fitting and towers positioning in LIDAR point cloud). The positioning accuracy of this compact LIDAR is obtained by comparing power tower coordinate from point cloud with the actual power tower coordinate measured by RTK (Real - time kinematic) technology. Figure 8 shows check points' accuracy, also this compact LIDAR's $0.286 \mathrm{~m}$ horizontal accuracy and $0.208 \mathrm{~m}$ elevation accuracy at $115 \mathrm{~m} \sim 125 \mathrm{~m}$ relative flight height can be calculate by root mean square error analysis method.

A research on safety hazards of transmission lines basing on LIDAR inspection data is carried out by You et al. (2013a, 2013b, 2014). A corresponding 3D power-line inspection software basing on this research results was also developed by Chen et al. (2013). With the help of this software, it is easily find safety hazards of transmission lines, shown as the red and blue balls in Figure 9.
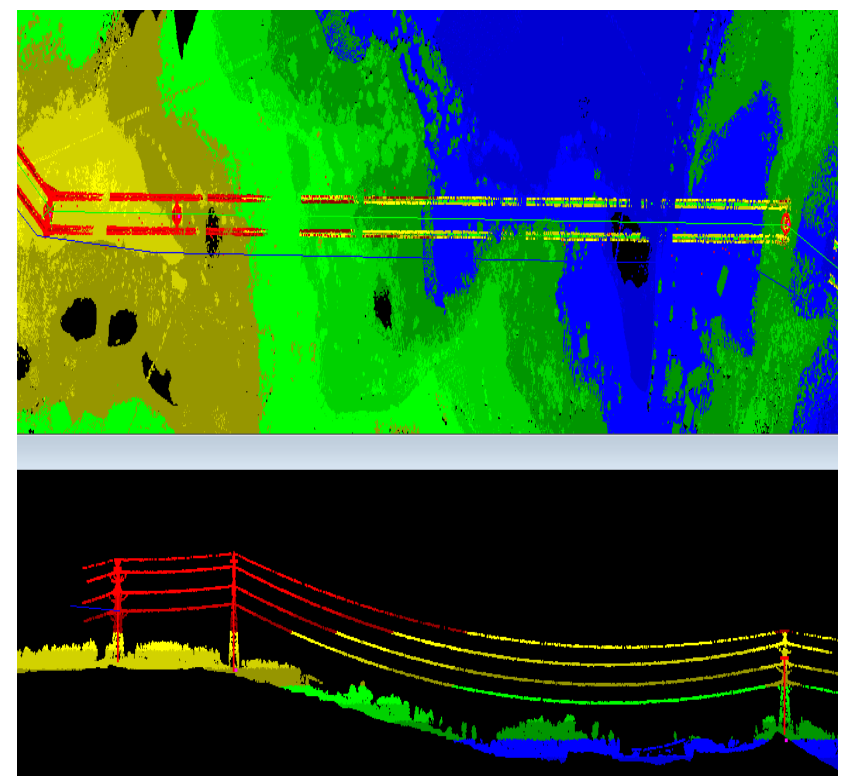

Figure 7. Laser point clouds of power lines 


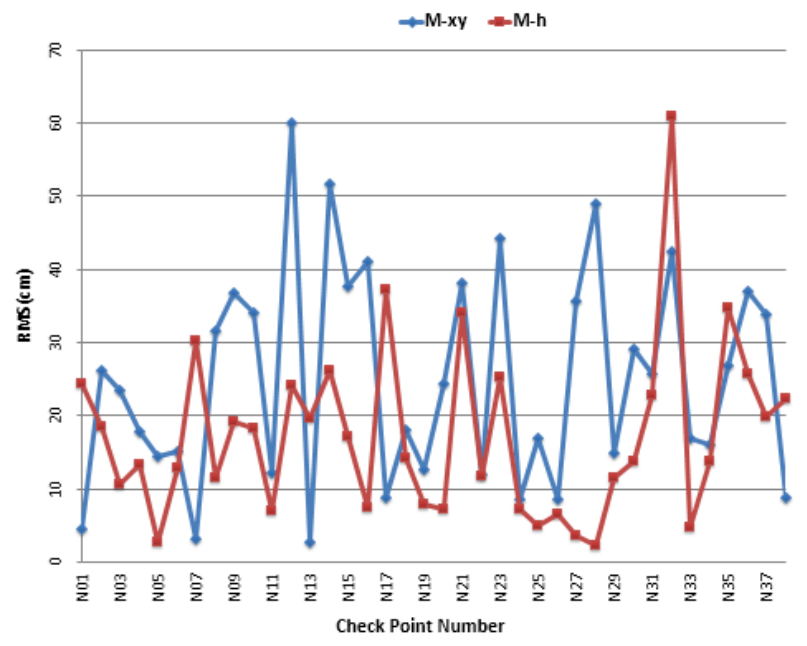

Figure 8. Positioning accuracy analysis of power-line inspection LIDAR

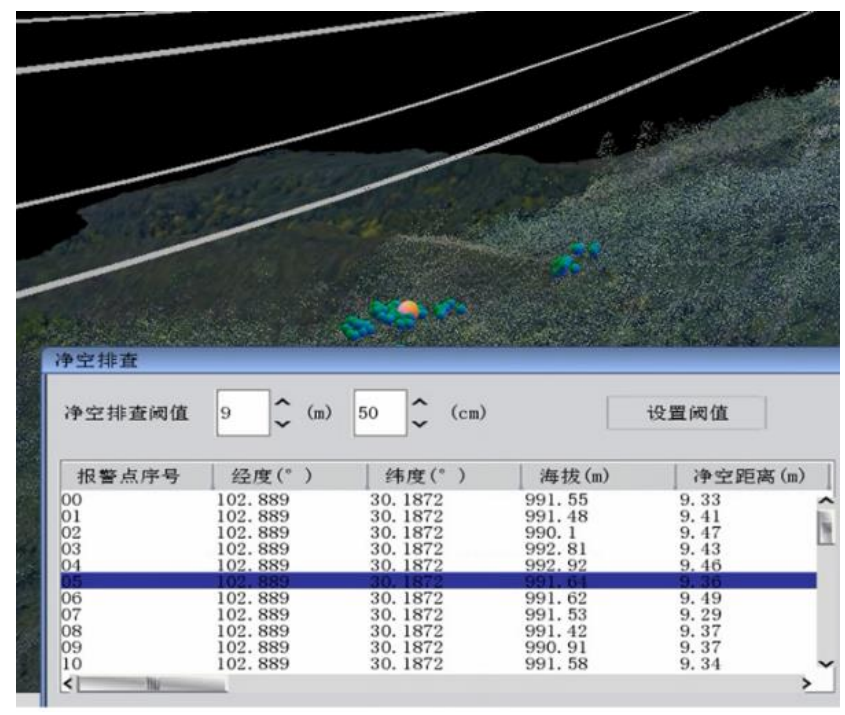

Figure 9. Investigation of safety distance of 3D inspection software

\section{CONCLUSION}

According to the power-line maintenance actual need in southwest region of China, a creative solution which integrates a compact LIDAR and an unmanned helium blimp is proposed. With the autonomous flight control algorithm coupling with laser ranging data of transmission lines, an unmanned blimp is guided along power lines in a limited space relative power lines, which improves inspection efficiency, reduces security risks and cost when inspects the transmission line, especially suitable for mountain patrol line of work.

After the LIDAR is miniaturized, its weight is only $22.5 \mathrm{~kg}$ (including battery). The test shows its plane position accuracy is less than $29 \mathrm{~cm}$, and its altitude accuracy is less than $21 \mathrm{~cm}$ (about 115m 125m height from the ground). Through test of a $500 \mathrm{kV}$ transmission lines, the usefulness of the power-line inspection system is verified.

\section{REFERENCES}

Chen Y. et al., 2013. Study of LIDAR Miniaturization and its Application in Power Supply System. Electric Power Survey \& Design, 2013(1), pp.70-73.

You A.Q. et al., 2013a. Applications of LIDAR in Patrolling Electric-Power Lines. The International Conference on Technological Advances in Electrical, Electronics and Computer Engineering (TAEECE2013), Mevlana University, Turkey, pp.111-115

You A.Q. et al., 2013b. Optimizations of a spatial distance check algorithm in power transmission system. Computer Engineering and Applications, 40(4), pp.298-300.

You A.Q. et al., 2014. Transmission wires fitting and towers positioning in LiDAR point cloud. Computer Science, 2014(7), pp.1209-0220. 